\title{
Innovation in the solid waste management industry: integrating neoclassical and complexity theory perspectives
}

\author{
Gaeta G. L. ${ }^{1}$, Ghinoi S. ${ }^{2}$, Silvestri F. ${ }^{3}$, Tassinari M. ${ }^{4}$
}

\begin{abstract}
Often considered a traditional labour intensive activity, in recent years, the solid waste management (SWM) industry has been largely interested in innovation. Nonetheless, the analysis of innovations in the SW industry is frequently confined to process innovation in the disposal segment, neglecting other kinds of innovation - such as product innovation and organizational innovation - in other segments. While several economic theoretical frameworks have been developed for interpreting eco-innovation in general, a specific analysis of innovation in each segment of SWM is still missing, despite the specificities of this sector. To fill this gap, this paper shows how complexity theory can be profitably used to integrate the more traditional neoclassical approach, offering a comprehensive theoretical framework to analyse innovation in the SWM industry from both a market and firm perspective (the neoclassical approach) and from a social perspective (the complexity theory framework). Four main typologies of the SW

\footnotetext{
${ }^{1}$ Department of Human and Social Sciences, University of Naples L'Orientale

${ }^{2}$ Department of Economics and Management, University of Helsinki (Finland), Department of International Business and Economics, University of Greenwich (UK).

${ }^{3}$ Department of Communication Science and Economics, University of Modena and Reggio Emilia (Italy), eco\&eco Ltd. (Italy), francesco.silvestri@unimore.it (corresponding author)

${ }^{4}$ Department of Law, University of Macerata (Italy)
} 
market system, exhibiting different kinds of innovation, are outlined: (i) a "traditional" landfill-oriented system; (ii) a modern "waste-to-energy" incinerator-oriented system; (iii) a "light recycling" system with integrated solutions and a selection performance that is lower than 50\%; and (iv) a "hard recycling" system.

\section{Table of contents}

1. Introduction 3

2. Process, product, and organizational innovation in the Solid Waste industry: an overview .5

3. Eco-innovations in the Solid Waste industry: the Neoclassical view and the "firm-side" perspective 10

4 The Complexity Theory and the "social-side" perspective in Solid Waste industry...... 13

5 Integrating neoclassical and complexity theory approaches.

6 Conclusions 24

References 26

JEL: O32, Q53, L97

Keywords: Solid Waste; Eco-innovation; Sociotechnical regime; Complexity Theory; Neoclassical theory 


\section{Introduction}

The solid waste management (SWM) industry is mostly considered a labour-intensive sector characterized by low innovation (Gomez-Ibanez et al., 1991; Massarutto, 2007). Nevertheless, in recent years, it has been marked by significant innovative activities (Pretty, 2003; OECD, 2008; Jegatheesan et al., 2009), developing both technological product and processrelated innovations and non-technological organizational innovations (James, 1997; Trigueiero et al., 2013; Cecere et al., 2014; Sica, 2016).

While several economic theoretical frameworks have been developed for interpreting ecoinnovation, a specific analysis of innovation in SWM is still missing. This is surprising since innovation in the SWM industry might play a crucial role in addressing environmental challenges and, therefore, might be important to promote sustainability (Milutinović et al., 2014, Antonopoulos et al., 2014) and to reduce climate change (Monni et al., 2006; Bhada-Tata and Hoornweg, 2016).

This paper aims to fill this gap in the literature by proposing a theoretical approach for analysing innovation in the SWM industry. Specifically, it shows how the Neoclassical approach can be combined with the Complexity Theory (CT) in order to build a comprehensive theoretical framework for examining innovation in the SWM industry.

A significant part of the existing studies on eco-innovation builds on a neoclassical theoretical approach (see, e.g., Boisot, 1992; Koschel, 1998; Rennings, 1998). According to this view, eco-innovations are mostly driven by market forces. Nevertheless, private investment in ecoinnovation is generally sub-optimal because the market fails to consider the double externality produced by such innovations, namely knowledge spillovers from research and development activities and reduction of environmental damage. In this vein, public intervention is deemed to play a crucial role. Policies fostering eco-innovations and their diffusion generally include 
(1) financial and nonfinancial incentives (e.g., grants and loans for industries to upgrade equipment); (2) technical assistance programmes (such as environmental audits, which help firms identify and implement environmental programmes); and (3) research and development programmes promoted and financed through private-public partnerships (see, among others, Nordhaus, 1969; Klemperer, 1990; Gallini, 1992; Denicolò, 1996; Maurer and Scotchmer, 2002, Porter, 1994; Zuckerman, 2003; Kremer, 1998; Foray, 2004; Scotchmer, 2004).

A second stream of literature on eco-innovations relates to evolutionary theories suggesting that innovation emerges from social interaction and historical processes (Arthur, 1989; David, 1985). According to this approach, the "technological regime" à la Nelson and Winter (1982) becomes a "sociotechnical regime" characterized by shared cognitive routines in a community affecting patterned development along technological trajectories (Geels and Schot, 2007). Indeed, Rennings (2000) argues that eco-innovation is not only about the technological dimension, but also related to organizational and social aspects. Nill and Kemp (2009) describe multiple approaches with evolutionary theory elements pertaining to the eco-innovation and sustainable innovation policy literature. They suggest that "there is a huge potential for an integrated evolutionary approach as paradigm for sustainable innovation policies" (Nill and Kemp, 2009: 677). In this vein, evolutionary theories can provide an in-depth overview of the innovation trajectories that lead to more sustainable practices in the SWM industry.

Consistent with this approach, CT can be used for investigating eco-innovation. Both approaches take inspiration from biology in observing agents' behaviour. They refuse the notion of perfect rationality for individuals, claiming that they interact in an uncertain environment, adapting their behaviour to external conditions in a changing setting. Finally, they both add emphasis to the public sector in orienting agents and reducing uncertainty (Arthur et al., 1997, Antonelli, 2011). 
In this paper we argue that the neoclassical view and the CT perspective can complement each other. The paper is organized as follows. Section 2 describes the methodology we applied for the literature review, upon which the theoretical framework developed in this paper is based. Section 3 provides an overview of the main innovations characterizing the SWM industry. Section 4 shows how the neoclassical view can capture some specific aspects of SWM innovative dynamics. Section 5 presents the CT perspective, which considers the "social side" of SWM innovation. Section 6 integrates the neoclassical and CT perspectives in a comprehensive theoretical framework to explain different kinds of innovation observed in the SWM industry. Section 7 provides some conclusive remarks.

\section{Methods for the literature review}

The theoretical framework for the analysis of innovation in the SWM industry proposed in this paper is developed starting from a systematic literature review on the topic. Drawing on established methodologies for literature reviews in economics and business (see, e.g., Gastel and Day, 2016; Gaur and Kumar, 2018), we based our work on five main steps.

First, as the research on innovation in the SWM industry began to draw attention the 2000s, we selected the period from 2000 to 2020 as the reference timespan for our analysis. Second, we analysed articles and reviews published in leading peer-reviewed journals in the fields of "Social Sciences"; "Economics, Econometrics and Finance"; and "Business, Management and Accounting". 5

\footnotetext{
${ }^{5}$ Specifically, we included the following journals: Business Strategy and the Environment; Computers, Environment and Urban Systems; Ecological Economics; Environment and Planning (A, B, C, D); Environment and Urbanization; Environment, Development and Sustainability; Environmental and Resource Economics; Environmental Development; Environmental Impact Assessment Review; Environmental Science and Policy; Habitat
} 
Third, to identify the relevant research published in these journals, we used the keywords and combinations "Solid-Waste-Management Industry", "Solid-Waste-Management Market", “Solid-Waste-Management Firm”, “Solid-Waste-Management Innovation”, “Solid-WasteManagement Eco-innovation", "Solid-Waste-Management AND Neoclassical-theory", "Solid-Waste-Management AND Economies-of-scale", "Solid-Waste-Management AND Production-scale", "Solid-Waste-Management AND Complexity-theory", "Solid-WasteManagement AND Sociotechnical”, "Solid-Waste-Management AND Circular-economy”.

Fourth, we explored the papers cited within this literature to capture other relevant studies (e.g., papers using different terminologies associated with innovation in the SWM industry, books and more generalized contributions that might be useful for our research). At the end of this stage, we obtained a list of 264 contributions (see Appendix A).

Finally, we reviewed each study's abstract and, where necessary, the full text to determine whether the articles were focused on innovation in the SWM industry. Thus, we individually screened all articles. This literature review led to the identification of relevant and recurrent evidence on innovation in the SWM industry. The theoretical framework for analysing innovation in the SWM industry proposed in this paper was eventually outlined by following this evidence.

International; International Journal of Environment and Sustainable Development; International Journal of Environmental Protection and Policy; International Journal of Environmental Resources; International Journal of Green Economics; International Journal of Innovation and Sustainable Development; International Journal of Social Ecology and Sustainable Development; International Journal of Sustainable Development and World Ecology; Journal of Cleaner Production; Journal of Environmental Planning and Management; Journal of Industrial Ecology; Resource and Energy Economics; Resources, Conservation and Recycling; Sustainability Switzerland; Sustainable Cities and Society; Waste Management; Waste Management and Research. 


\section{Process, product, and organizational innovation in the solid waste industry: an over- view}

Since the seminal work of Schumpeter (1919), innovation has been classified into three main typologies: process, product, and organizational innovation. The same classification applies to eco-innovation: Klemmer et al. (1999) and Rennings (2000) argue that eco-innovation addresses process, product, and organizational changes in firm management; Kemp and Arundel (2009) include in their definition of eco-innovation products, processes, techniques or systems that avoid or reduce environmental damage. Besides, Bauwens et al. (2020) distinguish between low-tech and high-tech innovations, which assume different forms according to the type of waste treatment strategy to which they are related. Considering the SWM industry, several innovations might be linked to these typologies, although some of them can hardly be classified under a single typology. As an example, the circular economy might be considered a systemic innovation in the SWM industry, and it relates to essential changes in the process, product, and organizational aspects of waste management (Kirchherr et al., 2018). This section provides a brief overview of the most recent innovations adopted in the SWM industry.

\subsection{Process innovation}

Process innovation in the SWM industry is mainly related to facilities operating in the segment of disposal. It deals with incinerating, pyrolyzing, or composting garbage to generate energy and new materials for other activities (e.g., agricultural activities). Even combinations of these techniques are available (Gohlke and Martin, 2007; Dunmade, 2013). With respect to downstream technologies, i.e., treating solid waste as an end-of-the-pipe product, three main categories exist: technologies that allow to obtain refused-derived fuel (RDF) from waste; technologies to obtain thermal and electric energy from waste incineration (Massarutto, 
2015); plasma torch incineration, a system that does not generate toxic gas emissions, particulates, or slag (Bosmans et al., 2013). Other innovative techniques involve biological and mechanical treatments of SW are aimed to reduce the amount of product to be landfilled.

Process innovation also relates to waste selection, i.e., recycling the end-of-the-pipe disposal (Pfeiffer and Rennings, 2001). New techniques include prepaid waste bags equipped with transponders, street dumpsters with electronic scales and skullcaps, or underground collection points to avoid the unpleasant visual impact of street dumpsters in constrained or historical areas (Sakai et al., 2008; Bing et al., 2016). Prepaid waste bags were created in Switzerland in the mid-1990s: their rationale is to sell plastic bags, validated by the local authority responsible for the SWM, as the only type accepted for the conferring of non-recyclable waste while selected SW can be conferred in free bags. Because of the expenditure in waste bags, households pay inversely to the effort in the selection they make as they are motivated to sort final SW as well to reduce the purchase of goods with a higher content of non-recoverable materials and packaging (De Jaeger and Eyckmans, 2015). To identify the amount of unsorted SW and to successfully charge households, new tracking systems have been introduced (Kanchanabhan et al., 2011). These systems are based on the application of electronic chips with transponders to plastic bags to identify and automatically memorize searchable data tagged through radiofrequency devices positioned on waste collection vehicles. This technology, called radio frequency identification (RFID), allows for the storage of data on the number of purchased bags, the weight of the conferred sacks, the number of conferment/emptying, and the geographical source of unsorted SW, which is useful information to make SWM more effective (Abdoli, 2009). Other ICT applications to the SWM industry rely on the adoption of software and electronic devices to track and measure garbage and to simplify the billing system (Boustani et al., 2011; Elia et al., 2015; Velvizhi et al., 2020). 


\subsection{Product innovation}

Product innovation is defined as the use of new concepts in producing consumer goods (Arthur et al. 1997). In the SWM industry, it mainly concerns the activity of eco-design, i.e., designing objects to minimize the environmental impact of the post-product lifecycle (Gottberg et al., 2006). This implies dematerialization, which might take the form of reducing materials used for production and for packaging (Nicolli and Mazzanti, 2011), e.g., through the reduction of product wrappings or the creation of refillable packaging systems (Nessi et al., 2015). Moreover, product innovation also concerns disassembling products in the dismantling phase to ease the recovery of components as raw materials (Vanegas et al., 2018). In their work on circular economy policies in the EU, Hartley et al. (2020) highlight the importance of innovative systems for more sustainable product design, production, and use as well as the main role of innovation in product end-of-life and waste.

\subsection{Organizational innovation}

Organizational innovation in the SWM industry mainly concerns waste collection and service charging. On the one hand, the presence of geographical constraints related to altimetry and urban sprawl leads to the implementation of innovative collection schemes based on door-to-door, kerbside, or proximity collection (Abbott et al., 2011). In some areas, collection is also carried out through "eco-mobiles", i.e., multicompartment vehicles providing collection services for exhausted oils, bulky waste, and electrical waste and electronic equipment (Zuo et al., 2020; Garrido-Hidalgo et al., 2020). In perched villages, even donkeys are used to address collection problems due to narrow streets and space constraints ${ }^{6}$.

\footnotetext{
${ }^{6}$ For this and other practical examples of unorthodox waste collection schemes, see https://zerowasteeurope.eu
} 
On the other hand, innovations in service charging have been proposed to relate more strictly the payment of the service to the amount of generated waste. The so-called Pay As You Throw (PAYT) tariff, which has been introduced in many European countries (Reichenbach, 2008), charges users on the basis of the quantity of waste presented for collection, which is observed directly by weighting or measuring its size, or indirectly by selling specific waste collecting bags. The PAYT tariff may be mixed with a flat rate tax based on parametric calculations, e.g., the number of family members (Elia et al., 2015).

\section{Eco-innovations in the solid waste industry: the neoclassical view and the "firm-side" perspective}

From the Neoclassical standpoint, market forces are the main driver for eco-innovations (Boisot, 1992). On the one hand, consumers' attitudes and preferences are crucial for forming the demand for environmentally friendly products and services. If such a demand exists, it de facto creates a potential market for eco-innovation (see, e.g., Hasla et al., 2008; Milfont and Duckitt, 2010; Cicatiello et al., 2020). On the other hand, competition among firms for the market or inside the market can significantly trigger innovation. The desire to leapfrog the incumbent in one market stimulates outsiders to look for radical innovations, and cohabiting in one market with other players leads to incremental innovations.

From this perspective, the neoclassical view finds a profitable connection with the Schumpeterian "creative destruction" approach as the "process of industrial mutation that incessantly revolutionizes the economic structure from within, incessantly destroying the old one, incessantly creating a new one" (Schumpeter, 1942). While market competition considered by the neoclassical theory describes the nature of incentives for innovation-faced market actors, the Schumpeterian approach opens the "black box" of structural and firm conditions that effectively establish these incentives and allow market dynamics to advance innovation. From this 
perspective, the Schumpeterian approach is well suited to explain how the neoclassical dynamic of innovation is protracted.

In particular, the distinction operated by Schumpeter between the so-called Mark I and Mark II appears to be the case in point (Malerba and Orsenigo, 1996). Mark I is characterized by low barriers and a high entry attitude, a low concentration of innovative activity, higher market instability, and the small-sized firms involved in traditional economic sectors (Schumpeter, 1919) while Mark II features low entrance, high technological and financial barriers, and highly concentrated and stable markets mostly populated by large firms that invest in R\&D activities (Schumpeter, 1942).

In a similar fashion, Pavitt (1984) identifies four categories of industries with respect to the nature of technological change, the features of the production process, market structure and other characteristics (Bogliacino and Pianta, 2010): (i) labour intensive, with small- and medium-size enterprises (SMEs) operating in traditional sectors with low barriers, innovation aimed at cost reduction and driven by materials and components providers, low appropriable and incremental, sectoral knowledge dominated by learning-by-doing and learning-by-using dynamics; (ii) capital intensive, with medium, large vertically integrated firms operating in industrial sectors (for instance metallurgy) with technological barriers, innovation aimed at cost reduction, originating from both outside (providers) and inside (R\&D), medium appropriability; (iii) specialized, with SMEs operating in instrumental sectors (typically machinery), low-medium barriers, innovation aimed at improving product quality and performance to customize the market, spreading from interaction with clients and practice, highly appropriable, knowledge dominated by learning-by-doing and tacit knowledge (Nonaka and Takeuchi, 1995); (iv) science-based, with large firms, mostly multinational, operating in technologyintensive sectors (electronics, pharma), high technological and financial barriers, innovation 
concentrated in the search for new products and driven by internal $R \& D$, highly appropriable through patents and secrecy, learning dominated by scientific knowledge.

This taxonomy is somewhat useful for illustrating SWM industry evolution. Until now, the SWM industry has covered the first two of Pavitt's trajectories, moving from (i) to (ii) during the 1990s, when SMEs, which were often municipality owned, dominated the market and were progressively replaced by larger and integrated firms with capital and technological intensity serving as entry barriers (Buclet, 2002).

This happened, at least in Europe, mainly because of an institutional push: EU legislation requested higher involvement of the private sector and the abandonment of the municipal provision of service, which allowed private firms to enter new territories. This happened mainly through vertical mergers and acquisitions (M\&As), i.e., M\&As between collectors and disposers, and horizontal M\&As, i.e., between organizations operating in the same segment. Indeed, M\&As have shifted a very fragmented SWM industry towards a more concentrated system, with larger operators competing in wider markets, with a potential positive impact on the total price of the SWM service (Bertossi et al., 2000). In passing from a labour-intensive to a more capital-intensive sector, innovation in the SWM industry has remained incremental and process-oriented, with the aim of reducing the costs of service provision. The degree of investments in R\&D is still low, and innovation is mainly embodied in capital equipment (Dijkgraaf and Vollebergh, 2004; Nicolli and Mazzanti, 2011).

The evolution of SWM toward a specialized or science-based industry is still difficult to predict, and some attempts in this regard, from the presence of multinational firms in foreign markets to the introduction of product innovations such as RDF, have not been successful yet. 


\section{The complexity theory and the "social-side" perspective in the solid waste industry}

An approach to eco-innovation that can be considered complementary to the firm-side view illustrated so far can be found in $\mathrm{CT}$, which pays a remarkable tribute to evolutionary thinking (Cecere et al., 2014). Evolutionary holistic approach (Faucheux et al., 1996) extends the analysis of innovations beyond the economic aspects and specifically looks at the interaction among technology innovation, social, ecological, and institutional systems (Sica, 2016; van den Bergh, 2007). Consistently with this perspective, CT claims that economic agents operate in a dynamic system and that their choices are the outcome of learning processes influenced by multiple interactions carried out in evolving and uncertain structures (Antonelli, 2011).

Lane and Maxfield $(1997,2005)$ identify three types of uncertainty intrinsic to the transforming action of agents: epistemological uncertainty, which is related to the real existence of the phenomenon (is a phenomenon true or not?); semantic uncertainty, which is related to the interpretation of the phenomenon by interacting agents (do all agents give the same meaning to the phenomenon?); ontological uncertainty, which is related to the vision of the world and the categories that describe it (is agent's representation of the state of the world still plausible after the evidence of the phenomenon?).

Innovation primarily generates an ontological uncertainty that must be guided. Two main instruments to address this issue are "narratives", i.e., cognitive processes that assign rationality to what is happening, and "scaffolds", i.e., various kinds of institutions such as public bodies, research and support centres, scientific journals, associations and unions that act as reference points in the uncertain conditions generated by a changing environment (Lane and Maxfield, 1997). Another distinctive construct of CT is provided by the notion of "artefact", defined as any manmade object embedding technical (or social) change and achieving some 
new functionality. The recurrent interaction among different kinds of agent (firms, individuals, and institutions) who design, produce, provide, trade, install and use artefacts gives rise to a "market system" (Lane and Maxfield, 1997; Lane, 2006).

Table 1 Agents, Artefacts and their interactions in the SWM Industry

$<$ Table 1 here >

Table 1 outlines the agents, artefacts, and interactions characterizing the SWM industry market system.

Agents operating in the SWM market system are heterogeneous. The regulators and planners at different administrative levels, starting at national-level regulation (supranational in the case of European Union countries, where waste directives originate from the European Commission) and arriving at the regional and municipal levels, often with different municipalities deciding to manage waste collectively in an integrated district. This kind of agent is public, with both policymakers and civil servants invested in the technical implementation of regulation. Industrial activities are run by private companies (often shared by public bodies, mostly municipalities) covering different segments of the market, typically collection and disposal as well as communication and environmental education. Equipment suppliers play a role in proposing new technical solutions to SW disposal, for instance new kind of dumpsters and vehicles, with a direct impact on the organization of collection; in the new scenario of SW reduction, a prominent part is played by product designers, whose work should be aimed to develop easily disposable products. More pronounced attention to recycling highlights the activity of extended responsibility and producers' associations with different materials (plastic products, glass products, paper and cardboard), called to follow the life cycles of products 
"from cradle to grave". Finally, the "front agents" of an integrated SWM system market are the households that are requested to begin the separate collection process.

As discussed in Section 3, different artefacts are present in the SWM industry, from simple (waste bags, domestic bins) and medium content (street dumpsters, even subterranean and gathered in the so-called "ecological islands", landfills) to progressively more technological content (collection vehicles, RDF, incinerators, RFID transponders and other tracking electronic equipment, waste-to-energy plants).

Their use by agents defines the different types of actions that substantiate SWM for each segment of the process, which CT refers to as "Interaction in the space of agents-artefacts". In this sense, the recourse to street dumpsters defines street and mixed collection, and it is compatible with landfilling and disposal based on incineration and with tax charging, even though PAYT schemes may rely also on modern street dumpsters. In the same way, waste bags and RFID are more effective with kerbside (and mixed) collection, recycling and PAYT.

Following this logic, CT provides a useful framework to identify different SW market systems based on different interactions in the agent-artefact space. More relevant, each type of interaction is both associated and determined by the closeness of the relationships among the agents; it is the same closeness that, according to CT, acts as driver for generative contacts and, ultimately, for innovation (Russo and Rossi, 2009).

\section{Integrating neoclassical and complexity theory approaches}

\subsection{Typologies of market systems in a complexity-neoclassical integrated framework}

The firm-side perspective derived by the neoclassical view and the social-side approach consistent with the CT can be fruitfully combined to outline a more comprehensive theoretical framework for understanding innovation in the SWM industry. The neoclassical view of innovation can be enriched by combining the characteristics of SWM firms associated with 
their production scale (Section 4) with the features of the system where they operate, which is mainly associated with the closeness of relations in agent-artefact spaces identified by the SWM industry (Section 5). From this perspective, a connection between structural and firm conditions for innovation, as described by referring to a Schumpeterian approach (see Section 4), and CT can be found. In fact, while factors such as barriers to entry, market concentration and firm size affect the competitive environment and the rate of innovation (Schumpeter's Mark I and II), the specific direction and quality of the innovations developed (i.e., the typology of goods and services effectively realized) is crucially constrained by the social context in which firms operate and, specifically, by the closeness of relations in agent-artefact spaces. Building on this intuition, a conceptual framework identifying specific typologies of the SWM market system, which exhibit different propensities towards innovation, can be outlined enriching the picture provided by the traditional classifications of markets and their potential for innovation.

Figure 1. Models of market system in a complexity-neoclassical integrated framework $<$ Figure 1 here >

By combining the neoclassical approach and the CT perspective, different SW market systems can be outlined (Figure 1): (i) a "traditional" landfill-oriented system; (ii) a modern "waste-to-energy" incinerator-oriented system; (iii) a "light recycling" system with integrated solutions and a selection performance that is lower than 50\%; and (iv) a "hard recycling" system where the selection performance is higher than $50 \%$.

(i) Although still relevant, the traditional system based on landfills is bound to disappear in the medium-long run (Wagner, 2011; Zacharof and Butler, 2004). Focusing on the European 
Union, 34\% of total waste was still disposed of in landfills in 2017 (last year available), with peaks in Greece, Romania, and - quite surprisingly - Finland ${ }^{7}$.

Indeed, from the firm-side perspective (Section 4), this typology of the market system has been prevalent, especially up to the 1990s. It is mainly characterized by traditional SMEs, with innovation aimed at cost reduction and driven by material and component providers. The typical company operating in this market system is a municipality-owned firm or a privatized one, when the enforcement of new regulation calls for it (e.g. in the European Union after 2000). From a CT standpoint, this model of innovation can call for either integration or separation of collector and disposer, and it is usually based upon street collection and the bestowing of collected SW to landfills for disposal. The relevant artefacts for this market system are street dumpsters, truck compactors and landfills. The interactions are monopolized by street collection and landfilling while the substantial nil involvement of households in collection does not call for any PAYT charging system.

According to CT, a necessary condition to observe the rise of innovation in a market system is to have interactive relationships among the agents. In the traditional market system, the nature of interactions is quite barren: relations are minimized to the public tender to find the collection- or the integrated-operator, the organization of collection by the entrusted operator, the contract between collector and disposer, and participation by household is absent. Consequently, innovation in this market system is depressed and dates back approximately 20 or 30 years in terms of operations to make landfills safer (new coating solutions, abating systems for dioxin) and for the automation of street collection (CCTV for a better approach of truck compactors to dumpsters as well as mechanical solutions for lifting and emptying dumpsters).

\footnotetext{
${ }^{7}$ Here, and hereafter, the data set is available at https://ec.europa.eu/eurostat/data/database, accessed on $18^{\text {th }}$ September 2020 .
} 
(ii) The "waste-to-energy" market system is based as the previous one on end-of-the-pipe facilities, but is represented in this case by incinerators revamped and upgraded for energy recovering plants. Again, official figures certify the relevance of this market system for $5.5 \%$ of the total waste treated in the EU, with peaks of up to $19 \%$ in Belgium and $23 \%$ in Denmark.

From a "firm-side" standpoint, it is generally a "hard industrial" market system, capital intensive, with medium-large and vertically integrated (collection+disposal) operators. This means a centrality for integrated multiutilities as well as the penetration of the market by large and capitalized companies such as energy and technology producers.

Following the CT perspective, the incinerator is the key artefact of this market system. The whole SW chain is oriented to feed it, meaning reducing any sophisticated selection that would subtract raw materials from the plant; consequently, the collection phase mainly draws upon undifferentiated street dumpsters. ${ }^{8}$ As there is no interest in rewarding a reduction in SW, schemes as PAYT are pointless, and standard waste taxes or fees are the common tool to finance the service. For this market system, relationships among agents are infrequent and limited to procedural exchanges involving experts and technicians; innovation in this market system is not the result of generative liaisons between agents but of the technology embedded in incinerators, and its origin is based in a sector external to the SW industry.

(iii) The "light recycling" system is a natural outcome of the integrated approach to SW management. It involves both recycling and end-of-the-pipe disposal. In the EU, it affects $46 \%$ of total municipal waste in 2017, raising constantly since 2015 .

\footnotetext{
${ }^{8}$ This description of the market system has recently been criticized by proponents of a "mixed" vision, suggesting that the primary need of waste-to-energy plants is not the fulfilment of the minimum optimal size but the search for efficiency in the selection of higher calorific materials and the discarding of other streams, in particular, wet waste. This is the perspective proposed by the "zero landfill" narrative (see infra).
} 
Given the coexistence of different SWM solutions, in this market system firms range from multiutility companies, at the heart of the service organization, to specialized SMEs, facing low-medium barriers to entry and active in particular segments of the value chain: social companies and cooperatives in the collection segment; private firms running treatment facilities, communication and agencies to deal with information campaigns directed to households and citizens.

From a CT perspective, the key artefacts range from waste bags, domestic bins and ecological points of collection to street dumpsters and incinerators (normally with energy recovery). The collection phase runs through a mixed system of street and kerbside collection, even inside the same municipality, with different numbers of materials selected. As a very assorted market system, the interactions among actors are frequent and varied: collectors and municipal policy makers debate stably to fit the national recycling targets; SW management involves quite deeply households, asking for an increasing effort in waste sorting and proposing to them evolving schemes of collection (separation of new materials, scheduled retreats, use of admitted plastic bags). As the higher involvement of citizens claims for more sophisticated payment schemes, PAYT tariffs progressively replace the waste tax. This asks for a change in the common artefacts, for instance in the street dumpsters, that are equipped with scales, skullcaps and electronic keys to register more precisely the quantity of SW conferred and to match it to the deliverer. Nonetheless, the existence of a wider network of agents favours the rise of innovation even in the form of assignment of new functions to existing artefacts: this is the case of RFID and transponders (see Section 3), commonly used in electronic ticketing systems and in logistics, and now applied to waste bags. The same happened with underground dustbins, a technology belonging to firms operating in the construction of interred parking lots and proposed as a solution to avoid ground occupation by dustbins in urban environments. 
(iv) Finally, the "hard recycling" is the market system of the integrated approach once addressed to a SW selection higher than $50-60 \%$. In the whole EU, Germany was over $60 \%$ in 2017 (67.3\%) while Slovenia (58.9\%), Austria (57.7\%), the Netherlands (55.9\%), Belgium (54.6\%), and Lithuania (52.5\%) passed the lower threshold. Hard recycling is the market system that fulfils the prospected evolution of SW management according to most advanced norms and regulations, such as the EU Priority Ladder Principle (Reggiani and Silvestri, 2017).

Banning the landfill and considering the incinerator a residual and temporary option means electing as central agents collectors and production chain consortia in an Enterprise Resource Planning (ERP) system (Favot et al., 2016). The firms operating in this market system are quite similar to the previous (iii), with an even deeper attention in communication agencies and service organizers such as a multiutility company. In this system the involvement of households is at the top, regarding not only the awareness in correctly selecting SW, but also the education in buying goods with lower contents of packaging. Interactions are characterized by the kerbside collection method and by PAYT charging, and main relevant artefacts are prepaid waste bags and tracking equipment. Innovation in this market system is organizational: the need to reach higher performances in collection and selection drives the introduction of minute solutions, such as the eco-mobiles and the cited use of donkeys as collection means in perched urban centres.

\subsection{Narratives in the SWM markets}

In the context of the theoretical framework developed above, CT comes to integrate the more traditional neoclassical approach in explaining innovation dynamics in the SWM industry. While the latter considers the role of firms in fostering innovation in the sector, it also allows to employ the key categories of CT for analysing the broader social context in which innovation is realized. As highlighted above (Section 5), along with agents, artefacts and their 
interconnections, two other notions are particularly useful to explain the current innovation dynamics in the SWM industry: narratives and scaffolds (see Table 2).

Through narratives, agents can identify the cognitive process that allows themselves to orient future actions, to compare it with other points of view, to address their action to mediumand long-run objectives.

In SW management, there are some recognizable narratives that play relevant roles in justifying and supporting some of the market systems illustrated in the previous section. The most famous are "Zero-waste" and "Zero-landfill” narratives.

Zero-waste promotes the feasibility of an almost complete elimination of SW disposed in end-of-the-pipe facilities, either landfills or incinerators. It is supported by an international network of non-profit associations, the Zero-Waste Alliance (ZWA), which helps industry and communities pursuing "a future without waste and toxic materials". According to ZWA, "Implementing Zero-waste will eliminate all discharges to land, water, or air that may be a threat to planetary, human, animal or plant health",

Another prominent narrative is the Zero-landfill option. Perceived as a deception by Zerowaste advocates, it promotes the integration of different waste management methods to achieve the objective of dismantling landfills in favour of a mixed system of recycling and waste-to-energy plants. On a global scale, the incineration segment still exhibits significant growth trends, mostly in EU countries experiencing a transition dominated by the aim of phasing out landfills as much as possible. There is a clear correlation among incineration, recycling and landfilling; countries that divert less than two kilograms/year per capita adopt a balanced combination of incineration and material recycling while countries that do not incinerate rely on landfills for more than $30 \%$ of their SW. According to proponents of Zero-

\footnotetext{
${ }^{9}$ www.zerowasteeurope.eu/about/principles-zw-europe, accessed November $21^{\text {st }} 2019$.
} 
landfill, this is a hint that incineration is complimentary, rather than contrary, to recycling in the effort of phasing-out landfills (Massarutto, 2015). Both the technical (Cossu, 2011; Brunner and Rechberger, 2015) and economic literatures (Massarutto et al, 2011) consider SW incineration as a key element of an integrated SW management strategy, emphasizing the complementarities between recycling and energy/thermal recovery from SW. The energy issue is stressed by promoters as a relevant environmental outcome of this approach, since energy from waste is $50 \%$ due to renewable materials contained in the waste flow, with a potential doubling of energy generated from waste in next years (Massarutto, 2015).

Finally, the Zero-landfill narrative disputes the presumed superiority of pure recycling with integrated methods relying also on waste-to-energy. From an economic perspective, the increasing marginal costs of SW selection, combined with the lower quality of materials collected for higher separation ratios and with imperfections and bottlenecks in the downstream segment of second-hand raw materials, suggest that recycling is not a viable option at any cost. Extreme recycling scenarios claim a kerbside system reaching $75 \%$ or more of separate collection, a realistic assumption for small cities and rural areas but not for urban ones (Massarutto, 2015). Jamasb and Nepal (2013) discuss the UK waste management strategy comparing a "business as usual" setting with the full implementation of the EU waste directive and finding that waste-to-energy is the dominant SW management technique in terms of social cost-benefit.

Table 2. Features of different SWM Market Systems. Source: authors

< Table 2 here >

\subsection{Scaffold in the SWM markets}

In addition to narratives, according to $\mathrm{CT}$, other useful tools in describing innovative environment dynamics are scaffolds (see Section 5). While narratives provide agents with a medi- 
um-long-run objective, leading the way to a possible change, scaffolds back them in the dayby-day relationship with an environment pressured by internal and external change. In fact, the main role of scaffolds is to strengthen the network ties among agents and artefacts through actions like the exploration of new options, dissemination, interpretation, circulation of information, and experimentation with solutions.

In the field of SWM, we can already identify the existence of relevant scaffolding structures. The most prominent is maybe the LIFE programme, EU's funding instrument for environmental and climate action. Since 1992, numerous LIFE projects have addressed the technical feasibility and financial viability of methods and technologies to enhance environmental performance in the waste sector. According to the LIFE Programme database ${ }^{10}$, from 1992 to 2013,579 out of 4.171 (13\%) financed projects focused on waste management issues; 369 of them are related to non-industrial waste, and 101 are identified as SW.

Other prominent SWM scaffolds can be identified in common platforms such as the aforementioned ZWA and in other initiatives implemented by environmental NGOs.

ZWA is an international network born in the US, with supranational, national and regional ramifications of non-profit associations conveying the Zero Waste narrative and helping firms and local communities to increase the percentage of recycling and reduce source waste. The aim of the network is to circulate information, best practices and standards to a community of current and potential members.

Many environmental NGOs act as scaffolds in different countries. This is the case for the Italian Legambiente, which, since 1994, has ranked Italian municipalities yearly based on the percentage of SW selection achieved, it organizes an annual national prize to award the high-

\footnotetext{
${ }^{10}$ LIFE Programme database, available at: http://ec.europa.eu/environment/life/project/Projects/index.cfm. Accessed November $20^{\text {th }} 2019$
} 
est achievement, and publishes many annual reports on the waste issue, including the annual dossier on criminal activities related to the environment and waste diversion.

Another important scaffolding role is played by international waste management fairs. The most relevant in Europe are the biennial fair of Munich (IFAT - International Trade Fair for Environment, Waste Water and Waste Disposal) and the annual fair in Rimini, Italy (Ecomondo) while Istanbul's REW Recycling and St. Petersburg's waste management, technology and equipment fairs are also gaining significant importance.

Finally, there are the international multidisciplinary journals that disseminate information and update the debate among researchers and practitioners on innovation and technical change in the waste industry.

\section{Conclusions}

While innovations have gained increasing importance in the SW industry, the analysis of their evolution over time has been rather neglected by literature on eco-innovation. Moreover, the same issue when addressed by the specialized literature in waste management seems to have been confined to process innovation and to the disposal sector. This paper has argued that Neoclassical and CT approaches can be combined to develop a comprehensive theoretical analysis of innovation in this industry.

With its emphasis on firms and market forces, Neoclassical theory is effective in illustrating the type of M\&A that concentrated the market during the ' 90 s and brought out integrated multiutilities as relevant players, a condition that is consistent with the low investment in R\&D and the lack of drastic innovations in the SW industry. On the other hand, CT allows an in-depth investigation of the functioning of the SWM industry based on the notion of a "market system". By combining these approaches, it is possible to identify different typologies of the SWM market system, each exhibiting different propensities towards innovation: (i) a "tra- 
ditional" landfill-oriented system; (ii) a modern "waste-to-energy" incinerator-oriented system; (iii) a "light recycling" system with integrated solutions and a selection performance that is lower than 50\%; and (iv) a "hard recycling" system where the selection performance is higher than $50 \%$.

While these typologies seem to coexist in various contexts, denoting different levels of development of this industry, they also identify possible stages of a trajectory of advancement of the SWM sector, which can be supported by national environmental public policies that are in line with the EU Priority Ladder Principle. From this perspective, the theoretical approach described in this paper provides a useful framework for understanding the development stage of the SWM industry. The proposed framework comes with specific policy implications. In fact, while it recognizes the relevance of policies for improving structural and firm conditions for innovation (associated with, for instance, the regulation of market competition, firms' economies of scale and investments for technological upgrading), it also suggests the relevance of public actions to promote a social context in which firms operate that is suitable for innovation by encouraging the closeness of the relations in "agent-artefact spaces". This latter aspect highlights the crucial relevance of cultural policies that are oriented to influence consumers' attitudes and ecological sensitivity that may foster pro-environmental behaviours, incentivizing eco-innovations.

From this perspective, while this paper offers useful insights to identify proper leverages for fostering sector innovation dynamics, further explorations in this field could be devoted to empirically testing the effectiveness of the proposed theoretical framework in explaining SWM innovation by comparing different experiences and performances over time. This may be a promising research line to improve our understanding of the SWM industry that has proven to play a key role in fostering environmental sustainability. 


\section{References}

Abbott, A., Nandeibam, S., O'Shea, L., 2011. Explaining the variation in household recycling rates across the UK. Ecological Economics 70(11), 2214-2223.

Abdoli, S., 2009. RFID Application in Municipal Solid Waste Management System. International Journal of Environmental Resources 3(3), 447-454.

Antonelli, C., 2011. The economic complexity of technical change; knowledge interaction and path dependence, in: Antonelli, C. (Ed.), Handbook on the Economic Complexity of Technological Change. Edward Elgar, Cheltenham.

Antonopoulos, I. S., Perkoulidis, S., Logothetis, G., Karkanias, C., 2014. Ranking municipal solid waste treatment alternatives considering sustainability criteria using the analytical hierarchical process tool. Resources, Conservation and Recycling 86, 149-159.

Arthur, W. B., 1989. Competing Technologies, Increasing Returns and Lock-in by Historical Events Economic Journal 99(394), 116-131.

Arthur, W. B., Durlauf, S. N., Lane D. A., 1997. The Economy as an Evolving Complex System II. Proceedings Volume XXVII, Santa Fe Institute Studies in the Science of Complexity, Reading, MA.

Bauwens, T., Hekkert, M., Kirchherr, J., 2020. Circular futures: What Will They Look Like? Ecological Economics 175, 106703.

Bertossi, P., Kaulard, A., Massarutto, A., 2000. Municipal waste management in Italy, in: Buclet, N., Godard, O. (Eds.), Municipal Waste Management in Europe: A Comparative Study in Building Regimes. Springer, Amsterdam, pp. 121-169. 
Bhada-Tata, P., Hoornweg, D., 2016. Solid Waste and Climate Change, in: Mastny, L. (Ed.), State of the World: Can a City Be Sustainable? Island Press, Washington, DC, pp. 239-255.

Bing, X., Bloemhof, J. M., Ramos, T. R. P., Barbosa-Povoa, A. P., Wong, C. Y., van der Vorst, J. G. A. J., 2016. Research challenges in municipal solid waste logistics management. Waste Management 48, 584-592.

Bogliacino, F., Pianta, M., 2010. Innovation and employment: a reinvestigation using re-vised Pavitt classes. Research Policy, 39(6), 799-809.

Boisot, M., 1992. Schumpeterian learning versus neoclassical learning: Development options for post-communist societies, in: Birley, S., MacMillan, I. C. (Eds.), International perspectives on entrepreneurship research. North Holland, Amsterdam, pp. 3-5.

Bosmans, A., Vanderreydt, I., Geysen, D., Helsen, L., 2013. The crucial role of Waste-toEnergy technologies in enhanced landfill mining: A technology review. Journal of Cleaner Production 55, 10-23.

Boustani, A., Girod, L., Offenhuber, D., Britter, R., Wolf, M. I., Lee, D., Miles, S., Biderman, A., Ratti, C., 2011. Investigation of the waste-removal chain through pervasive computing. IBM Journal of Research and Development 55(1-2), 11:1.

Brunner, P., Rechberger, H., 2015. Waste to energy - key element for sustainable waste management. Waste Management 37, 3-12.

Buclet, N., 2002. Alternative scenarios for a sustainable MSW and the national and European trajectories, in: Buclet, N. (Ed.), Municipal waste management in Europe: European policy between harmonisation and subsidiarity. Springer, Amsterdam, pp. 197-208.

Cecere, G., Corrocher, N., Gossart, C., Ozman, M., 2014. Lock-in and path dependence: an evolutionary approach to eco-innovations. Journal of Evolutionary Economics 24, 1037-1065. 
Cicatiello, L., Ercolano, S., Gaeta, G. L., Pinto, M. 2020. Willingness to pay for environmental protection and the importance of pollutant industries in the regional economy. Evidence from Italy. Ecological Economics 177, 106774.

Cossu, R., 2011. Waste management, energy production, healthcare: amazing similarities. Waste Management 31(8), 1671-1672.

David, P., 1985. Clio and the Economics of QWERTY. American Economic Review 75(2), 332-337.

De Jaeger, S., Eyckmans, J., 2015. From pay-per-bag to pay-per-kg: The case of Flanders revisited. Waste Management and Research 33(12), 1103-1111.

Denicolò, V., 1996. Patent Races and Optimal Patent Breadth and Length. Journal of Industrial Economics 44(3), 249-265.

Denicolò, V., 2002. Sequential innovation and the patent-antitrust conflict. Oxford Economic Papers 54(4), 649-668.

Dijkgraaf, E., Vollebergh, H. R. J., 2004. Burn or bury? A social cost comparison of final waste disposal methods. Ecological Economics 50(3-4), 233-247.

Dunmade, I., 2013. Sustainability issues in innovative waste reduction technology adoption and assimilation. International Journal of Environmental Protection and Policy 1(4), 59-67.

Elia, V., Gnoni, M. G., Tornese, F., 2015. Designing Pay-As-You-Throw schemes in municipal waste management services: A holistic approach. Waste Management 44, 188-195.

Favot, M., Veit, R., Massarutto, A., 2016. The evolution of the Italian EPR system for the management of household Waste Electrical and Electronic Equipment (WEEE). Technical and economic performance in the spotlight. Waste Management 56, 431-437.

Foray, D., 2004. The Economics of Knowledge. MIT University Press, Cambridge.

Gallini, N., 1992. Patent Policy and Costly Imitation. RAND Journal of Economics 23(1), 5263. 
Garrido-Hidalgo, C., Javier Ramirez, F., Olivares, T., Roda-Sanchez, L., 2020. The adoption of Internet of Things in a Circular Supply Chain framework for the recovery of WEEE: The case of Lithium-ion electric vehicle battery packs. Waste Management 103, 32-44.

Gastel, B., Day, R.A., 2016. How to write and publish a scientific paper (8th edn.). ABCCLIO, Denver. Gaur, A. S., Kumar, M. 2018. A systematic approach to conducting review studies: An assessment of content analysis in 25 years of IB research. Journal of World Business, 53(2), 280-289.

Geels, F. W., Schot, J. W., 2007. Typology of sociotechnical transition pathways. Research Policy 36(3), 399-417.

Ghinoi, S., Silvestri, F., Steiner, B., 2020. The role of local stakeholders in disseminating knowledge for supporting the Circular Economy: a network analysis approach. Ecological Economics 169, 106446.

Gohlke, O., Martin, J., 2007. Drivers for innovation in waste-to-energy technology. Waste Management and Research 25(3), 214-219.

Gomez-Ibanez, J. A., Meyer, J. R., Luberoff, D. E., 1991. The Prospects for Privatising Infrastructure: Lessons from US Roads and Solid Waste. Journal of Transport Economics and Policy 25(3), 259-278.

Gottberg, A., Morris, J., Pollard, S., Mark-Herbert, C., Cook, M., 2006. Producer responsibility, waste minimisation and the WEEE Directive: Case studies in eco-design from the European lighting sector. Science of the Total Environment 359(1-3), 38-56.

Hansla, A., Gamble, A., Juliusson, A., \& Gärling, T., 2008. Psychological determinants of attitude towards and willingness to pay for green electricity. Energy policy 36(2), 768-774.

Hartley, K., van Santen, R., Kirchherr, J., 2020. Policies for transitioning towards a circular economy: Expectations from the European Union (EU). Resources, Conservation and Recycling 155, 104634. 
Jamasb, T., Nepal, R., 2013. Issues and options in waste management: a social cost-benefit analysis of waste-to-energy in the UK. Resources, Conservation and Recycling 54(12), 13411352.

James, P., 1997. The Sustainable Circle: a new tool for product development and design. Journal of Sustainable Product Design 2, 52-57.

Jegatheesan, V., Liow, J. L., Shu, L., Kim, S. H., Visvanathan, C., 2009. The need for global coordination in sustainable developme nt. Journal of Cleaner Production 17(7), 637-643.

Kanchanabhan, T. E., Abbas Mohaideen, J., Srinivasan, S., Kalyana Sundaram, V. L., 2011. Optimum municipal solid waste collection using geographical information system (GIS) and vehicle tracking for Pallavapuram municipality. Waste Management and Research 29(3), 323339.

Kemp, R., Arundel, A., 2009. Measuring eco-innovation. UNU-MERIT Working Papers, 2009-017.

Kirchherr, J., Piscicelli, L., Bour, R., Kostense-Smit, E., Muller, J., Huibrechtse-Truijens, A., Hekkert, M., 2018. Barriers to the Circular Economy: Evidence From the European Union (EU). Ecological Economics 150, 264-272.

Klemmer, P., Lehr, U., Lobbe, K., 1999. Environmental Innovation, Vol. 3. Analytica, Berlin. Klemperer, P., 1990. How Broad Should the Scope of Patent Protection Be? RAND Journal of Economics 21(1), 113-130.

Koschel, H., 1998. Incentives of Environmental Policy Instruments to Innovation in Neoclassical Models: a Survey. Paper presented on the Workshop "Model Specification in GEM-E3Elite", July 9 - 10 1998, Stockholm School of Economics, Stockholm.

Kremer, M., 1998. Patent Buyouts: A Mechanism for Encouraging Innovation. Quarterly Journal of Economics 113(4), 1137-1167. 
Lane, D. A., 2006. Hierarchy, complexity, society, in: Pumain, D. (Ed.), Hierarchy in Natural and Social Sciences. Springer, Dordrecht, pp. 81-119.

Lane, D. A., Maxfield, R., 1997. Foresight, Complexity, and Strategy, in: Arthur, B., Durlauf, S., Lane, D. A. (Eds.), The Economy as an Evolving Complex System II. Addison Wesley, CA.

Lane, D. A., Maxfield, R., 2005. Ontological Uncertainty and Innovation. Journal of Evolutionary Economics 15, 3-50.

Malerba, F., 2000. Economia dell'innovazione. Carocci Editore, Roma.

Malerba, F., Orsenigo, L., 1996. Schumpeterian patterns of innovation are technologyspecific. Research Policy 25, 451-478.

Massarutto, A., 2007. Municipal waste management as a local utility: Options for competition in an environmentally-regulated industry. Utilities Policy 15(1), 9-19.

Massarutto, A., 2015. Economic aspects of thermal treatment of solid waste in a sustainable WM system. Waste Management 37, 45-57.

Massarutto, A., de Carli, A., Graffi, M., 2011. Material and energy recovery in integrated waste management systems: A life-cycle costing approach. Waste Management 31(9-10), 2102-2111.

Maurer, S., Scotchmer, S., 2002. The Independent-Invention Defence in Intellectual Property. Economica 69(276), 535-547.

Mazzanti, M., Nicolli, F., Biolcati Rinaldi, D., 2012, Multi-Tasking in the Waste Realm. Theoretical and Empirical Insights on Management and Disposal Performances. EuroEconomica 31(5), 88-101.

Milfont, T. L., Duckitt, J., 2010. The environmental attitudes inventory: A valid and reliable measure to assess the structure of environmental attitudes. Journal of environmental psychology $30(1), 80-94$. 
Milutinović, B., Stefanović, G., Dassisti, M., Marković, D., Vučković, G., 2014. Multicriteria analysis as a tool for sustainability assessment of a waste management model. Energy 74, 190-201.

Monni, S., Pipatti, R., Lehtil, A., Savolainen, I., Syri, S., 2006. Global climate change mitigation scenarios for solid waste management. VTT publications 603, Julkaisija Vuorimiehentie (SF).

Nelson, R., Winter, S., 1982. An evolutionary theory of economic change, Harvard University Press, Cambridge.

Nessi, S., Rigamonti, L., Grosso, M., 2015. Packaging waste prevention activities: A life cycle assessment of the effects on a regional waste management system. Waste Management and Research 33(9), 833-849.

Nicolli, F., Mazzanti, M., 2011. Diverting Waste: The Role of Innovation, in OECD (Ed.), Invention and Transfer of Environmental Technologies. OECD Publishing, Paris, pp. 127-150. Nill, J., Kemp, R., 2009. Evolutionary approaches for sustainable innovation policies: From niche to paradigm? Research Policy 38, 668-680.

Nonaka, I., Takeuchi, I., 1995. The Knowledge-Creating Company: How Japanese Companies Create the Dynamics of Innovation. Oxford University Press, Oxford.

Nordhaus, W., 1969. Invention growth, and welfare; a theoretical treatment of technological change. MIT University Press, Cambridge.

OECD, 2008. Environmental Policy, Technological Change and Patents. OECD Publishing, Paris.

Pavitt, K., 1984. Sectoral Patterns of Technological Change: towards a Taxonomy and a Theory. Research Policy”13(6), 343-373. 
Pfeiffer, F., Rennings, K., 2001. Employment impacts of cleaner production - Evidence from a German study using case studies and surveys. Business Strategy and the Environment 10(3), $161-175$

Porter, R., 1994. The Biographical Dictionary of Scientists. Oxford University Press, New York.

Pretty, J., 2003. Social Capital and the Collective Management of Resources. Science 302(5652), 1912-1914.

Reggiani, C., Silvestri, F., 2017. Municipal solid waste, market competition and the EU policy. Environmental and Resource Economics 71(2), 457-474,

Reichenbach, J., 2008. Status and prospects of pay-as-you-throw in Europe - A review of pilot research and implementation studies. Waste Management 28(12), 2809-2814.

Rennings, K., 1998. Towards a Theory and Policy of EcoInnovation - Neoclassical and (Co)Evolutionary Perspectives. Centre for European Economic Research. Discussion Paper 9824.

Rennings, K., 2000. Redefining innovation - eco-innovation research and the contribution from ecological economics. Ecological Economics 32(2), 319-332.

Russo, M., Rossi, F., 2009. Cooperation Networks and Innovation: A Complex Systems Perspective to the Analysis and Evaluation of a Regional Innovation Policy Programme. Evaluation 15(1), 75-99.

Sakai, S., Ikematsu, T., Hirai, Y., Yoshida, H., 2008. Unit-charging programs for municipal solid waste in Japan. Waste Management 28(12), 2815-2825.

Schumpeter, J.A., 1919 [1951]. The sociology of imperialisms, in: Sweezy, P.M. (Ed.), Imperialism and social classes, 1-130. Augustus, New York

Schumpeter, J., 1942. Capitalism, Socialism and Democracy. Harper, New York. Scotchmer, S., 2004. Innovation and Incentives. MIT University Press, Cambridge. 
Sica, E., 2016. Economic theories of eco-innovations: A comparison between the neoclassical and evolutionary approaches. International Journal of Innovation and Sustainable Development 10(1), 87-102.

Silvestri, F., Spigarelli, F., Tassinari, M., 2020. Regional development of Circular Economy in the European Union: a multidimensional analysis. Journal of Cleaner Production 255, 120218.

Triguero, A., Moreno-Mondéjar, L., Davia, M. A., 2013. Drivers of different types of ecoinnovation in European SMEs. Ecological Economics 92, 25-33.

van den Bergh, J. C. J. M., 2007. Evolutionary thinking in environmental economics. Journal of Evolutionary Economics 17, 521-549.

Vanegas, P., Peeters, J. R., Cattryss, D., Tecchio, P., Ardente, F., Mathieux, F., Dewulf, W., Duflou, J. R., 2018. Ease of disassembly of products to support circular economy strategies. Conservation and Recycling Resources 135, 323-334.

Velvizhi, G., Shanthakumar, S., Das, B., Pugazhendhi, A., Priya, T.S., Ashok, B., Nanthagopal, K., Vignesh, R., Karthick, C., 2020. Biodegradable and non-biodegradable fraction of municipal solid waste for multifaceted applications through a closed loop integrated refinery platform: Paving a path towards circular economy. Science of the Total Environment 731, 138049.

Wagner, J., 2011. Incentivizing sustainable waste management. Ecological Economics 70(4), 585-594.

Zacharof, A. I., Butler, A. P., 2004. Stochastic modeling of landfill processes incorporating waste heterogeneity and data uncertainty. Waste Management 24(3), 241-250.

Zuckerman, S., 2003. New wave of Energy Efficient Refrigerator. www.ecomall.com/greenshopping/icebox2.htm. Inewpage (accessed 13 March 2020) 
Zuo, L., Wang, C., Sun, Q., 2020. Sustaining WEEE collection business in China: The case of online to offline (O2O) development strategies. Waste Management 101, 220-230.

\section{Figures and Tables}

Figure 1. Models of market system in a complexity-neoclassical integrated framework

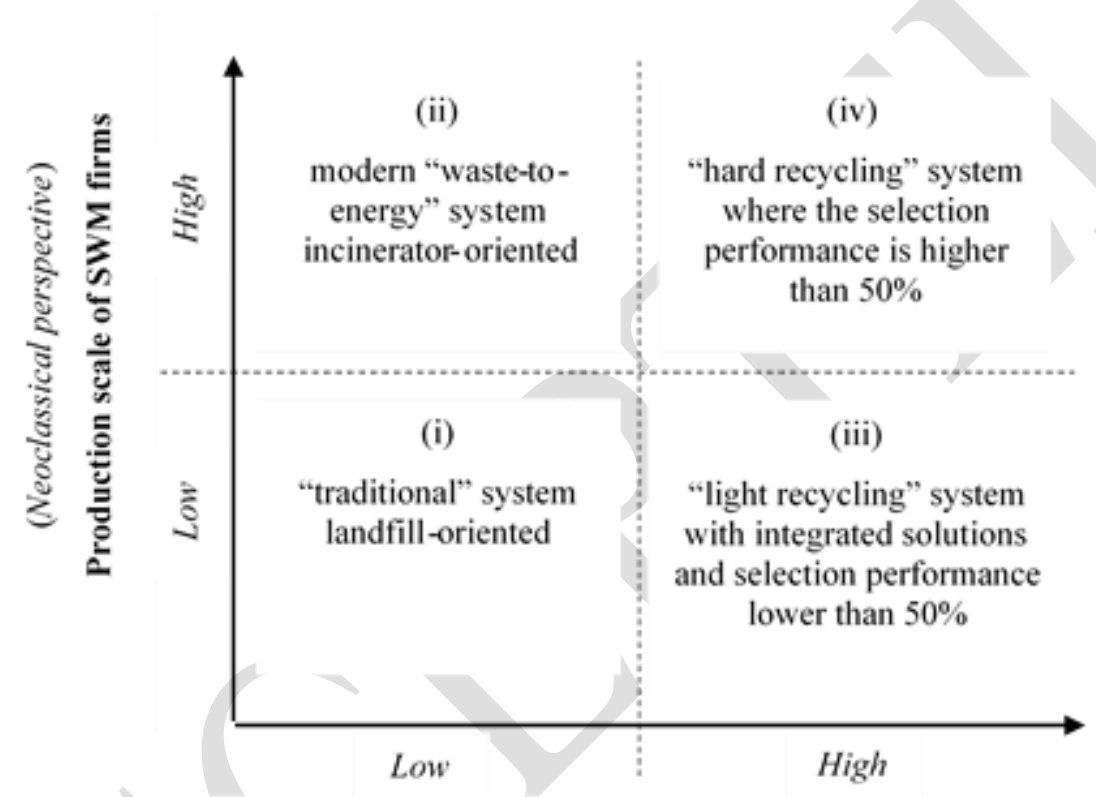

Closeness of agents' relations in the MWM Industry

(CT perspective)

Table 1 Agents, Artefacts and their interactions in the SWM Industry

\begin{tabular}{ll}
\hline Categories & Items \\
\hline National policymakers (regulators) & Regional planners \\
& Municipal planners \\
& District organizers/controllers \\
Agents & Collection operators \\
& Disposer operators \\
& Equipment suppliers
\end{tabular}




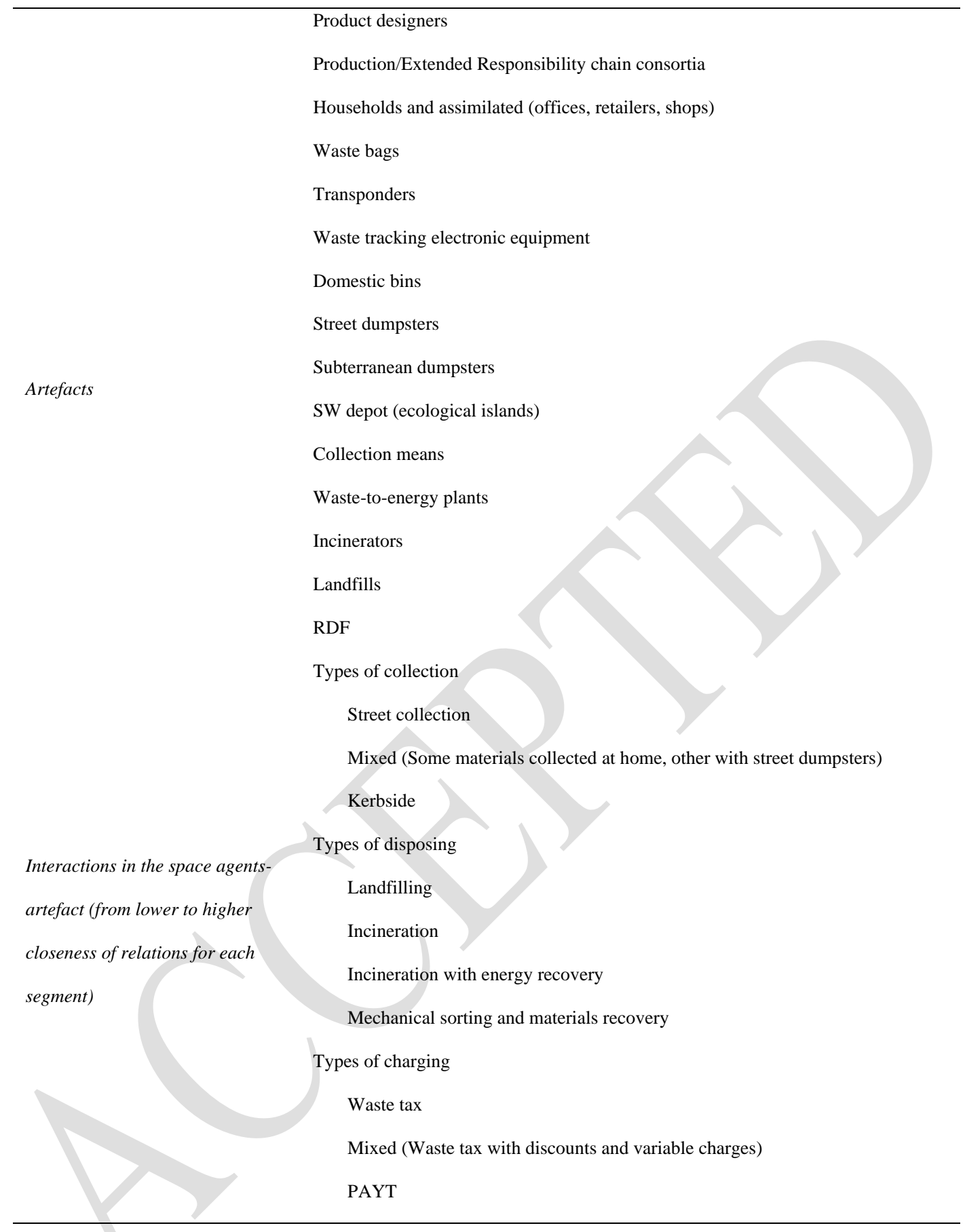

Table 2. Features of different SWM Market Systems. Source: authors

\begin{tabular}{lllll}
\hline & i. Traditional & ii. Waste to Energy & iii. Light Recycling & iv. Hard Recycling \\
\hline Agents & Collectors, & Collectors, & Collectors, & Collectors, \\
& Disposers (formerly mu- & Disposers, & Disposers, & Disposers, \\
& nicipality-owned firms), & Integrated operators (multiutili- & Integrated operators (multiutili- & Integrated operators (multiutilities), \\
& Local planners & ties), & ties), & Households, \\
& Energy producers, & Households, & Communication \& media experts
\end{tabular}




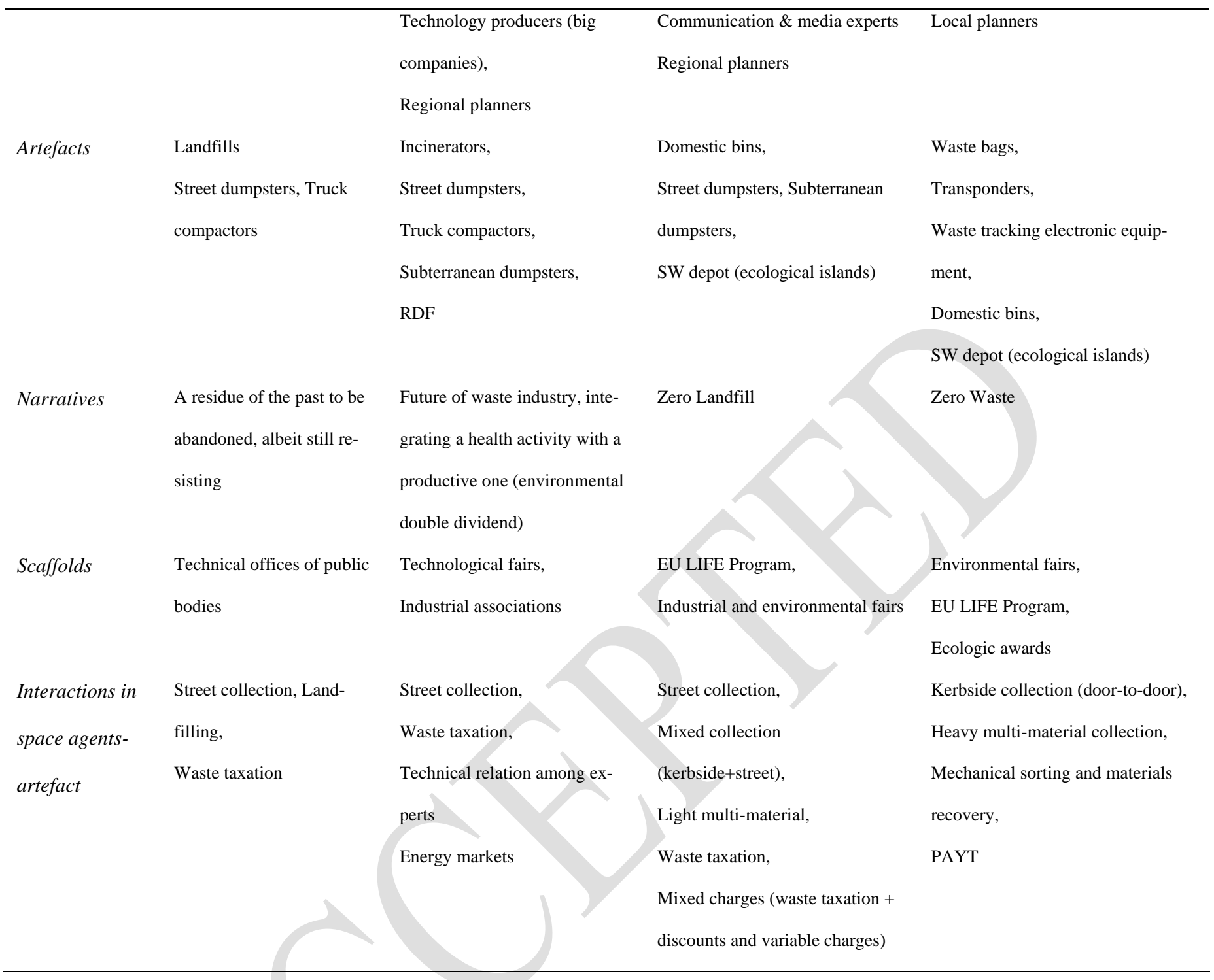

